\title{
DARE Train-the-Trainer Pedagogy Development Using 2-Round Delphi Methodology
}

\author{
Wei Wei Dayna Yong, ${ }^{1}$ Phek Hui Jade Kua, ${ }^{2}$ Swee Sung Soon, ${ }^{3}$ \\ Pin Pin Maeve Pek, ${ }^{4}$ and Marcus Eng Hock Ong ${ }^{4}$ \\ ${ }^{1}$ Yong Loo Lin School of Medicine, National University of Singapore, Singapore \\ ${ }^{2}$ Department of Emergency Medicine, KK Women's and Children's Hospital, Singapore \\ ${ }^{3}$ Department of Pharmacy, National University of Singapore, Singapore \\ ${ }^{4}$ Department of Emergency Medicine, Singapore General Hospital, Singapore
}

Correspondence should be addressed to Wei Wei Dayna Yong; daynayong6@gmail.com

Received 2 June 2016; Accepted 4 August 2016

Academic Editor: Han-Ping Wu

Copyright (C) 2016 Wei Wei Dayna Yong et al. This is an open access article distributed under the Creative Commons Attribution License, which permits unrestricted use, distribution, and reproduction in any medium, provided the original work is properly cited.

\begin{abstract}
The Dispatcher-Assisted first REsponder programme aims to equip the public with skills to perform hands-only cardiopulmonary resuscitation (CPR) and to use an automated external defibrillator (AED). By familiarising them with instructions given by a medical dispatcher during an out-of-hospital cardiac arrest call, they will be prepared and empowered to react in an emergency. We aim to formalise curriculum and standardise the way information is conveyed to the participants. A panel of 20 experts were chosen. Using Delphi methodology, selected issues were classified into open-ended and close-ended questions. Consensus for an item was established at a 70\% agreement rate within the panel. Questions that had 60\%-69\% agreement were edited and sent to the panel for another round of voting. After 2 rounds of voting, 70 consensus statements were agreed upon. These covered the following: focus of CPR; qualities and qualifications of trainers; recognition of agonal breathing; head-tilt-chin lift; landmark for chest compression; performance of CPR when injuries are present; trainers' involvement in training lay people; modesty of female patients during CPR; AED usage; content of trainer's manual; addressing of questions and answers; updates-dissemination to trainers and attendance of refresher courses. Recommendations for pedagogy for trainers of dispatcher-assisted CPR programmes were developed.
\end{abstract}

\section{Introduction}

Out-of-hospital cardiac arrest (OHCA) is one of the main causes of death, of which $65.4 \%$ occur at home in Asia [1]. Annually, there are 700,000 cardiac arrest cases in Europe and more than 400,000 cases in America [2]. In Singapore, the annual incidence of OHCA is at least 1,400 cases, of which only $3 \%$ survived to discharge [3].

International studies have shown that early cardiopulmonary resuscitation (CPR) improves the chances of survival [4]. Furthermore, a review of several large-scale studies emphasised the importance of dispatcher-assisted CPR in improving bystander CPR and OHCA survival rates $[5,6]$.

Locally, the bystander CPR rate is only around 20\% [3]. Clearly, there is a need to improve these rates which can be done via a local dispatcher-assisted CPR programme. To do so, we conceived a simplified programme for the lay public to learn how to perform effective CPR and use an AED while guided by a medical dispatcher over the telephone.

Traditional CPR classes focus heavily on the rescuer working alone. In our programme, we focus on the rescuer cooperating with the dispatcher. The trainers of this community outreach programme are individuals who are both CPR and AED certified. They guide the participants during the hands-on session, providing constructive feedback and correcting their CPR technique. Currently, there is no formal train-the-trainer curriculum for a dispatcher-assisted $\mathrm{CPR}$ training programme. This train-the-trainer model is an established tool used by organisations which gather content from experts to educate trainers pooled from the community, in order to enable them to instruct target audiences. The advantage of such a model is that it can be propagated 
in the long term by multiple trainers who can disseminate information back to the community in a timely fashion, making this cost-effective and sustainable [7].

As of now, there is no formal pedagogy to train the trainers how to teach the lay population dispatcher-assisted CPR. We aim to write a structured train-the-trainer curriculum to regulate and homogenize the type of information and the way it is conveyed to the participants during the sessions.

\section{Methods}

2.1. Setting. The Dispatcher-Assisted first REsponder (DARE) programme is an hour long programme and includes an explanatory video and an instructor-led hands-on session. This is shorter than the usual CPR and AED certification course which spans at least 4 hours and does not include a humorous video. The participants will learn to recognise a cardiac arrest, dial the local emergency number, familiarise themselves with the medical dispatcher's commands, and perform effective CPR on manikins and how to use an AED.

2.2. Study Design. To come up with the trainers' curriculum, consensus was gathered using the Delphi approach [8]. This method involves recruiting a panel of experts to answer questions pertaining to the areas of concern.

The study was exempted from institutional review board approval.

2.3. Study Participants. A panel of 20 local experts wellversed in cardiopulmonary resuscitation (CPR), from 9 different institutions, was invited to be a part of the study. These included those who are medically trained, who are personally involved in overseeing the current DARE curriculum, and/or who are first-aid instructors. Their areas of expertise varies and include, but are not limited to, emergency medicine, outof-hospital cardiac arrest, and education.

2.4. Study Protocol and Data Collection. First, a pilot group, comprising 4 people who were familiar with DARE or were involved in studies that used the Delphi method, was created. The principal investigator worked with the pilot group to draw up a questionnaire based on literature review and the feedback from trainers. After discussing with the pilot group, we edited the questionnaire and chose to focus on questions related to 10 core areas. These areas are as follows:

(1) The focus of general CPR

(2) How the train-the-trainer session should be conducted

(3) Recognition of cardiac arrest

(4) How CPR should be taught

(5) Teaching the usage of AED

(6) Precourse reading materials

(7) Frequently asked questions

(8) Trainers' qualities and qualifications

(9) Assessment of trainers

(10) Continuity of the programme
The expert panel was created and care was taken not to include the panellists from the pilot group.

2.4.1. Round One of Delphi Method. The first-round Delphi questionnaire was distributed to the experts in December 2015 through an online questionnaire portal (SurveyMon$\left.\mathrm{key}^{\mathrm{TM}}\right)$. They could provide any specific comments perceived to be necessary to drive a primary consensus. The first round was completed after about one month in January 2016. This first questionnaire consisted of dichotomous answers (yes/no), ranking questions, multiple choice questions, and some required open-ended responses. Openended responses allowed the experts to give their input, to clarify the interpretation of the question, and to expose common fallacies. Primary consensus was achieved when $70 \%$ of respondents were in agreement for dichotomous and multiple choice question.

This cut-off point was used based on previous studies suggesting that a minimum of $70 \%$ agreement is needed for validity when using the Delphi method [9-11].

2.4.2. Round 2 of Delphi Method. The expert panel was informed of round one's preliminary results and of their individual comments. Data of which items had obtained consensus and which had not, with the overall agreement percentage obtained by the experts, were presented to the panel. Items that either did not obtain consensus in the first round but had 60-69\% agreement or had some ambiguity in phrasing were included in the second questionnaire. Comments and additional options from round one were taken into consideration and included into round two as well. Where possible, the exact phrasing as round one was used. For multiple choice questions with 60-69\% agreement and ranking questions, where possible, the questions were converted to yes/no options for clarity.

The second round of Delphi was administered through the previous portal in February 2016 for 3 weeks with the same expert panel. Questions with more than 70\% of agreement were regarded as a secondary consensus. We summarized the issue lists from the primary and secondary consensus as the final step by reviewing them via e-mail to establish the recommendations on the curriculum for a dispatcherassisted train-the-trainer programme. The English language (without translation) was used as the working language in all steps. Figure 1 is a summary of the process undertaken for the 2-Round Delphi Methodology.

2.4.3. Statistical Analyses. For each item, statistical analysis was performed and the agreement rates were calculated with percentages and frequencies.

\section{Results}

20 experts participated in this study. After opening up the first round of Delphi surveying for 1 month, 25 issues arrived at a consensus. After opening up the second round of Delphi surveying for the same amount of time, an additional 14 issues arrived at a consensus. A total of 70 consensus statements were agreed by the expert panel. No agreement was reached 


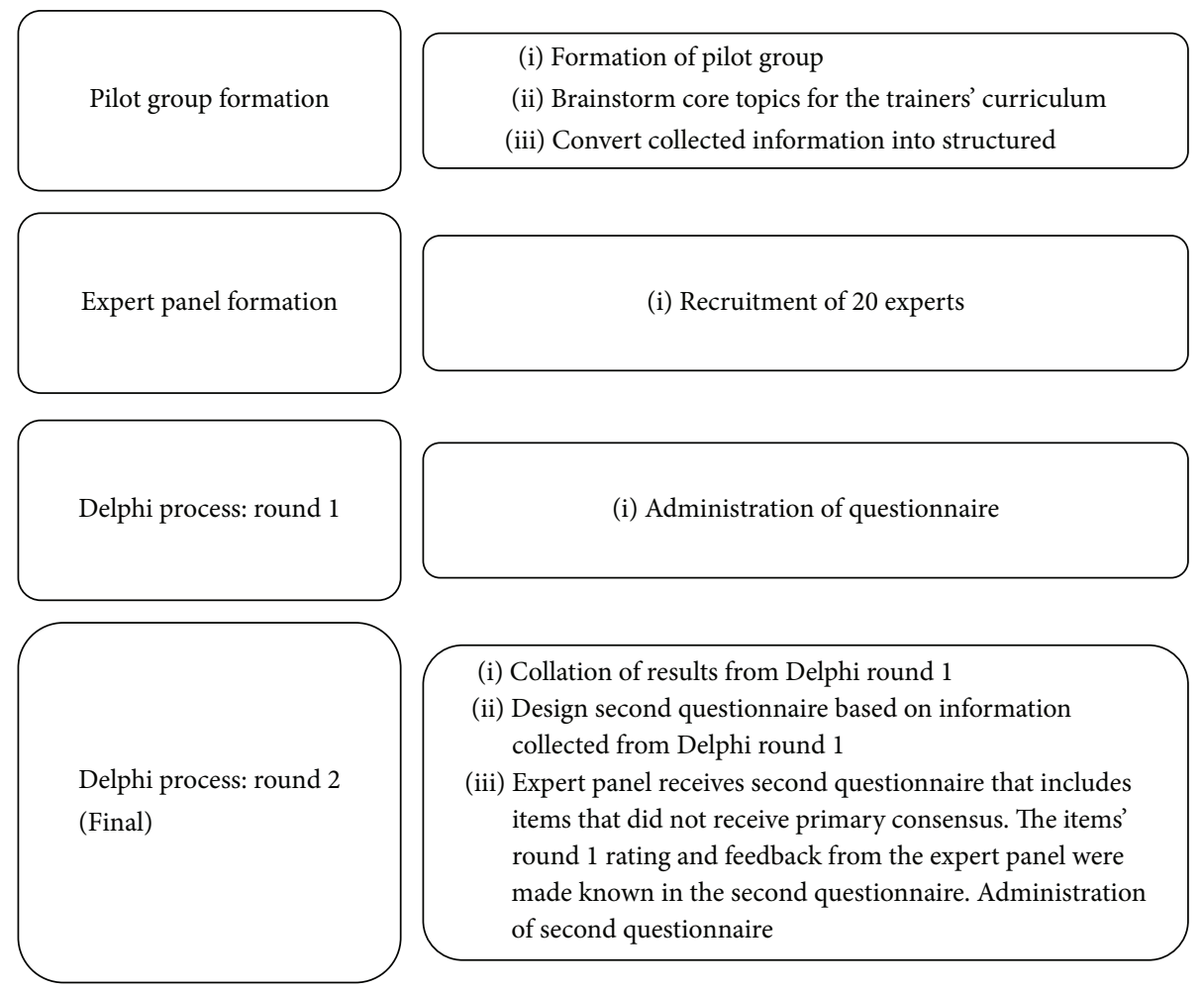

Figure 1: Flow of process.

on 11 issues. A summary of the items that received consensus and did not receive consensus can be found in Tables 1 and 2, respectively.

\section{Discussion}

This study is the first of its kind and aims to gather the viewpoints of experts regarding a suitable curriculum for a dispatcher-assisted CPR, train-the-trainer programme. We found that there was $100 \%$ agreement on elements that revolved around these core domains:

(1) How the train-the-trainer session should be conducted

(2) Recognition of cardiac arrest

(3) How CPR should be taught

(4) Precourse reading materials

(5) Frequently asked questions

(6) Assessment of trainers

All of the experts agreed that the trainers should correct the hand-positioning of participants when carrying out CPR. The instructors could instruct them of the changes verbally or physically move the participants' hands into the right position. $25 \%$ of the experts disagreed that trainers should physically correct the participants' hand position. One of the experts gave feedback that it could be potentially awkward for a male trainer to touch a female participant's hand.

$100 \%$ of the experts agreed that the curriculum should include a question-and-answer guide so that the trainers will give standardised answers confidently. Common topics that participants in previous DARE training sessions brought up include the need for a good Samaritan law, the risk of being sued, and the fear of breaking ribs during CPR.

The expert panel agreed unanimously that, in assessing the trainers, their ability to conduct the lessons and classroom management skills are important aspects. This suggests that it is not just the theory of resuscitation that should be taught to the trainers but educational methods employing domains including psychology and communication.

Agonal breathing is abnormal breathing that is reported to be present in about $40 \%$ of OHCA $[12,13]$. It is often confused by bystanders as a sign of life $[12,14]$ causing CPR to be delayed or withheld, which is associated with poorer outcomes. It was agreed that bystanders' descriptions of agonal breathing should be taught to the trainers. Trainers should be familiar with layman's description of agonal breathing, which could include gasping and noisy breathing $[12,13]$ and emphasise to lay participants the importance of recognising agonal breathing as a sign of cardiac arrest. They should also dispel any misconception of agonal breathing being a sign of life.

The panel experts all agreed that recognising cardiac arrest, calling 995, and cooperating with the dispatcher for telephone-assisted resuscitation, as well as how to find and use an AED, were important areas that should be included in the curriculum.

Traditionally studies have shown that CPR should not be omitted in the context of a traumatic cardiac arrest [15]. 100\% of our experts agreed that the curriculum should specify that CPR be carried out in a victim who has had a fall. 


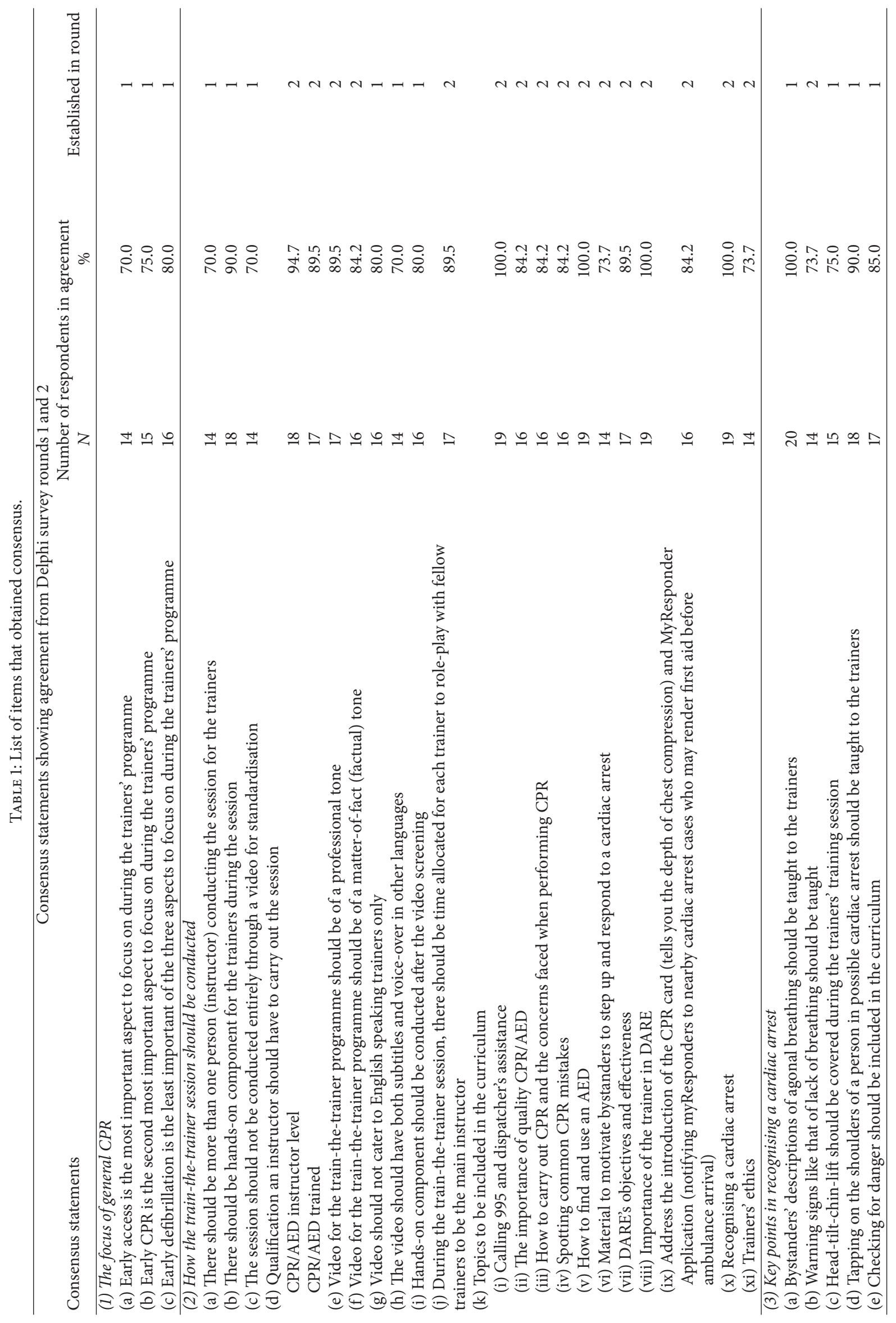




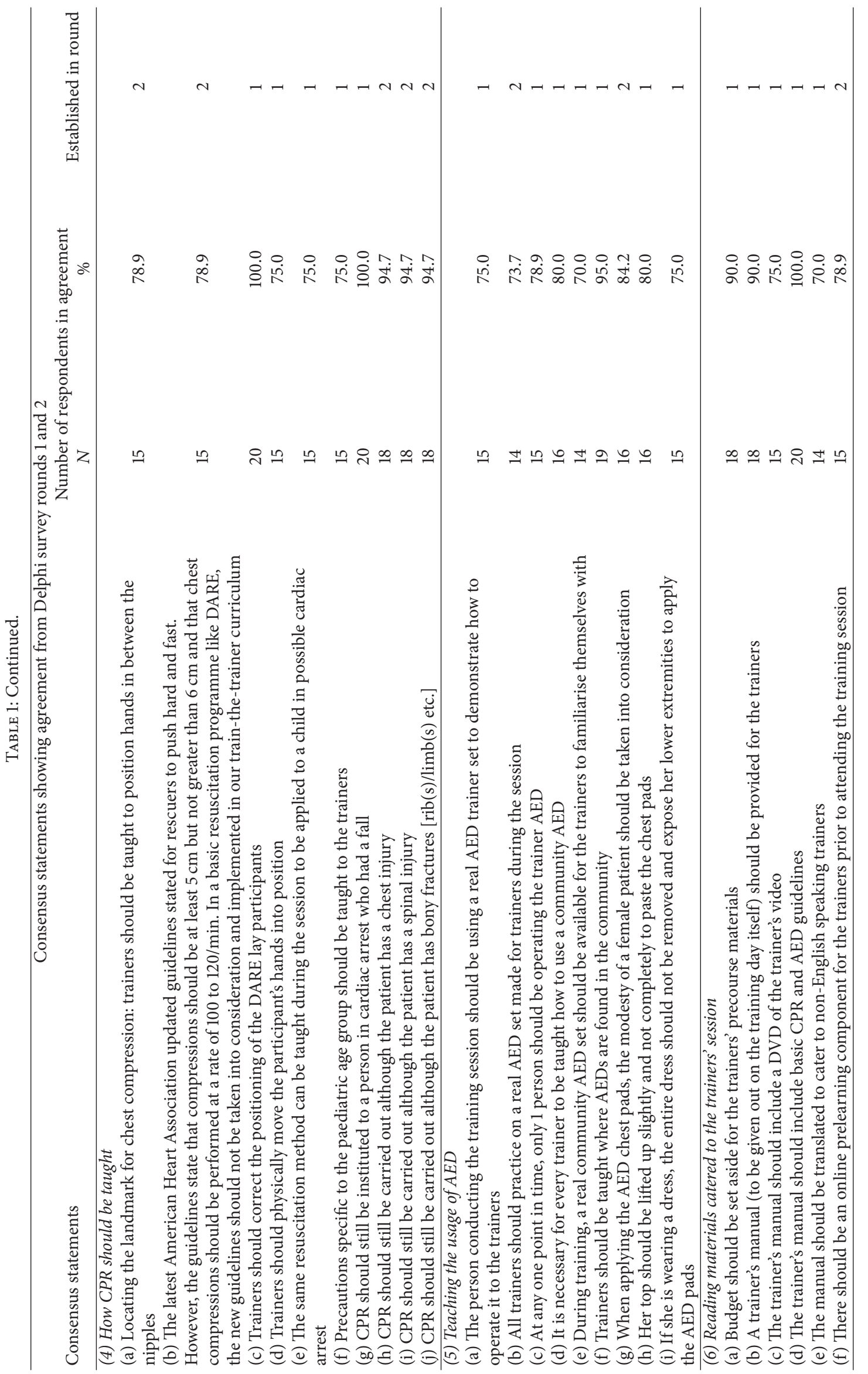




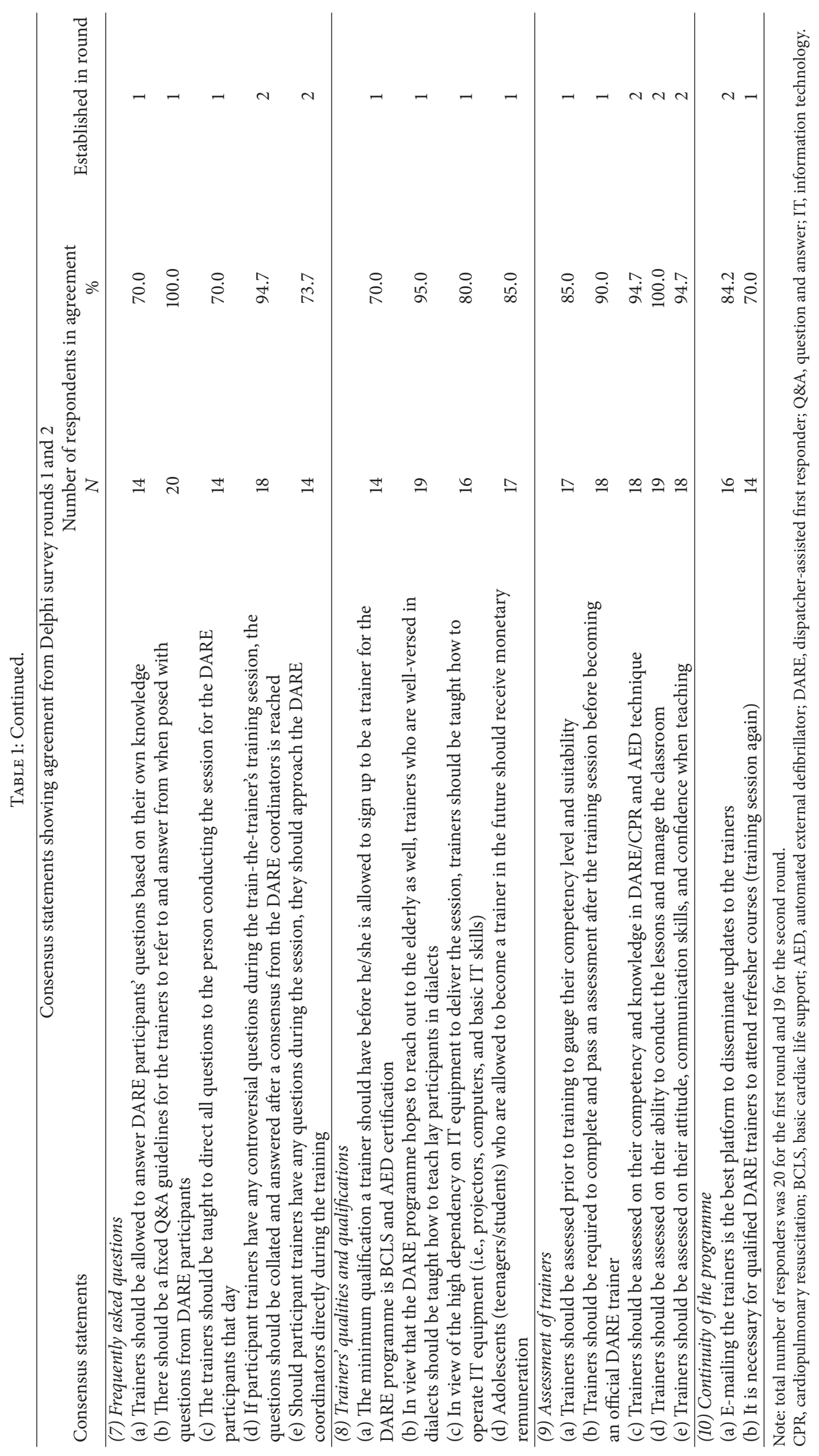


TABLE 2: List of items which did not achieve consensus.

Issues on which consensus could not be reached

Statements

Respondents

$N$

$\%$

The instructor who carries out the train-the-trainer session should be a healthcare professional with a current BCLS certificate

Yes

No

8

Duration of training session

2 hours

1.5 hours

1 hour 9

What should be the maximum number of trainers per session for the

train-the-trainer programme? (This is in view that there is only one instructor conducting the programme)

4 to 6

12 to 20

In view that agonal breathing is reported to be present in about $40 \%$ of OHCA, is agonal breathing the only kind of respiration the trainer should be taught to look out for before doing CPR

Yes

No

10

Warning signs like that of impending collapse (chest pain, diaphoresis/perspiration, shortness of breath, and drowsiness) should be taught

Yes

No

6

Are dispatchers able to teach head-tilt-chin-lift over the phone

Yes

9

No

11

Trainers should be taught to not teach head-tilt-chin-lift to the lay participants

Yes

No

11

Materials to motivate trainers attending the trainer's course should be covered in the curriculum

Yes

Importance of maintaining airway should be covered in the curriculum

How trainers can enhance their communication skills should be covered in the curriculum

Yes

What should the maximum ratio of participant trainers : AED trainer set be

$1: 1$ to $2: 1$

When applying the AED pads, should the entire bra be removed or just the bra straps be removed 
TABle 2: Continued.

Issues on which consensus could not be reached

\begin{tabular}{|c|c|c|}
\hline \multirow{2}{*}{ Statements } & \multicolumn{2}{|c|}{ Respondents } \\
\hline & $N$ & $\%$ \\
\hline \multicolumn{3}{|c|}{$\begin{array}{l}\text { Should participant trainers have any questions during the session? They should } \\
\text { e-mail the question(s) to an address provided }\end{array}$} \\
\hline Yes & 10 & 52.6 \\
\hline No & 9 & 47.4 \\
\hline \multicolumn{3}{|c|}{$\begin{array}{l}\text { Should participant trainers have any questions during the session? They should } \\
\text { write the questions down on a piece of paper given }\end{array}$} \\
\hline Yes & 12 & 63.2 \\
\hline No & 7 & 36.8 \\
\hline \multicolumn{3}{|c|}{$\begin{array}{l}\text { Should adolescents who are in uniform groups be allowed to be a trainer? (i.e., } \\
\text { adolescents whose CCA is NCC/scouts/girl guides/St John's/other uniform groups) }\end{array}$} \\
\hline Yes & 12 & 63.2 \\
\hline No & 7 & 36.8 \\
\hline \multicolumn{3}{|c|}{ How often should trainers be updated with new information } \\
\hline Once a month & 0 & 0.0 \\
\hline Once every 6 months & 2 & 10.5 \\
\hline Once a year & 5 & 26.3 \\
\hline Whenever there are updates & 12 & 63.2 \\
\hline Never & 0 & 0.0 \\
\hline
\end{tabular}

The experts unanimously agreed that the materials given out to the trainees should include current national CPR and AED guidelines. With this material given out before course, it allows the trainers to refresh their memory on the guidelines, reducing unnecessary questions that might be asked during the programme.

\section{Strengths}

The Delphi method was employed in preference to other consensus-achieving methodologies because it is convenient to implement. It is the most time-efficient methodology, as the questionnaires are completed individually, at the expert's own convenience. Consolidation of the results gathered is released for all experts to review, allowing a certain amount of interaction between them [11]. Additionally, this anonymous method [8] eliminates bias resulting from personal status and institutional role in achieving consensus [16].

\section{Limitations}

In this study, there were a few limitations. Firstly, the expert panel was made up of people chosen by invitation to partake in this study. As such, their opinions may not be representative of universal viewpoints. All of the experts were from Singapore. They have worked in Singapore and are familiar with the local resuscitation field. Hence the results might only be relevant in the local setting and should this pedagogy be extended into other settings, certain changes would have to be made or the questionnaire could be redistributed to experts of that specific country. Additionally, the entire study from the administration of the first questionnaire to the closure of the second questionnaire took place within a 2.5 months' period. Within that amount of time, it could be possible that new research in the area might have arisen in the meantime and that the results gathered from this study were overridden by the new research.

\section{Future Studies}

Based on our study, we would like to come up with a trainthe-trainer programme that can be launched at a national level. This model appears to be a feasible approach to promote adoption of curricular content on a national scale. Using the results of our study, we can also come up with precourse materials for the trainers to review prior to attending the session. They can even use the materials to revise their knowledge before teaching lay participants.

Future studies can include an audit of both trainers and participants, to see if the execution of the resultant programme is effective. Comparison of the outcomes of the trainers before and after the implementation of the trainthe-trainer curriculum should be made. The difference in performance of the trainers after having undergone the current training programme and the new trainer's curriculum should be evaluated as well. Gaps should be addressed and improvements should be made accordingly based on qualitative and quantitative surveys.

\section{Conclusion}

Recommendations for pedagogy for trainers of dispatcherassisted CPR programmes were developed using the Delphi 
method. These recommendations should be validated in practical settings.

\section{Ethical Approval}

The Centralised Institutional Research Board (CIRB iSHaRe Ref 201509-00085) has approved the study and waivered the need for consent.

\section{Competing Interests}

The authors report a grant from Temasek Cares, during the conduct of the study. The authors declare that there are no competing interests regarding the publication of this paper.

\section{References}

[1] M. E. H. Ong, S. Do Shin, N. N. A. De Souza et al., "Outcomes for out-of-hospital cardiac arrests across 7 countries in Asia: the Pan Asian Resuscitation Outcomes Study (PAROS)," Resuscitation, vol. 96, pp. 100-108, 2015.

[2] S. Sans, H. Kesteloot, and D. O. Kromhout, "The burden of cardiovascular diseases mortality in Europe," European Heart Journal, vol. 18, no. 8, pp. 1231-1248, 1997.

[3] H. Lai, C. V. Choong, S. Fook-Chong et al., "Interventional strategies associated with improvements in survival for out-ofhospital cardiac arrests in Singapore over 10 years," Resuscitation, vol. 89, pp. 155-161, 2015.

[4] T. D. Valenzuela, D. J. Roe, S. Cretin, D. W. Spaite, and M. P. Larsen, "Estimating effectiveness of cardiac arrest interventions: a logistic regression survival model," Circulation, vol. 96, no. 10, pp. 3308-3313, 1997.

[5] B. J. Bobrow, M. Panczyk, and C. Subido, "Dispatch-assisted cardiopulmonary resuscitation: the anchor link in the chain of survival," Current Opinion in Critical Care, vol. 18, no. 3, pp. 228-233, 2012.

[6] L. L. Culley, J. J. Clark, M. S. Eisenberg, and M. P. Larsen, "Dispatcher-assisted telephone CPR: common delays and time standards for delivery," Annals of Emergency Medicine, vol. 20, no. 4, pp. 362-366, 1991.

[7] R. A. Orfaly, J. C. Frances, P. Campbell, B. Whittemore, B. Joly, and $\mathrm{H}$. Koh, "Train-the-trainer as an educational model in public health preparedness," Journal of Public Health Management \& Practice, vol. 11, no. 6, pp. S123-S127, 2005.

[8] C.-C. Hsu and B. A. Sandford, "The Delphi technique: making sense of consensus," Practical Assessment, Research \& Evaluation, vol. 12, no. 10, pp. 1-8, 2007.

[9] A. P. Verhagen, H. C. W. De Vet, R. A. De Bie et al., "The Delphi list: a criteria list for quality assessment of randomized clinical trials for conducting systematic reviews developed by Delphi consensus," Journal of Clinical Epidemiology, vol. 51, no. 12, pp. 1235-1241, 1998.

[10] B. M. A. Huisstede, H. S. Miedema, A. P. Verhagen, B. W. Koes, and J. A. N. Verhaar, "Multidisciplinary consensus on the terminology and classification of complaints of the arm, neck and/or shoulder," Occupational and Environmental Medicine, vol. 64, no. 5, pp. 313-319, 2007.

[11] C. M. Fernández-Llamazares, Y. Hernández-Gago, M. Pozas et al., "Two-round Delphi technique for the consensual design of a paediatric pharmaceutical care model," Pharmacological Research, vol. 68, no. 1, pp. 31-37, 2013.
[12] A. Bång, J. Herlitz, and S. Martinell, "Interaction between emergency medical dispatcher and caller in suspected out-ofhospital cardiac arrest calls with focus on agonal breathing. A review of 100 tape recordings of true cardiac arrest cases," Resuscitation, vol. 56, no. 1, pp. 25-34, 2003.

[13] J. J. Clark, M. P. Larsen, L. L. Culley, J. R. Graves, and M. S. Eisenberg, "Incidence of agonal respirations in sudden cardiac arrest," Annals of Emergency Medicine, vol. 21, no. 12, pp. 14641467, 1992.

[14] T. D. Rea, "Agonal respirations during cardiac arrest," Current Opinion in Critical Care, vol. 11, no. 3, pp. 188-191, 2005.

[15] B. Bouillon, T. Walther, M. Krämer, and E. Neugebauer, "Trauma and circulatory arrest. 224 preclinical resuscitations in Cologne in 1987-1990," Der Anaesthesist, vol. 43, no. 12, pp. 786-790, 1994.

[16] M. K. Murphy, N. A. Black, D. L. Lamping et al., "Consensus development methods, and their use in clinical guideline development," Health Technology Assessment, vol. 2, no. 3, pp. $1-4,1998$ 


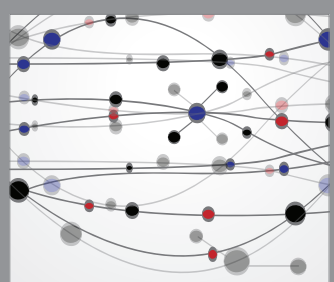

The Scientific World Journal
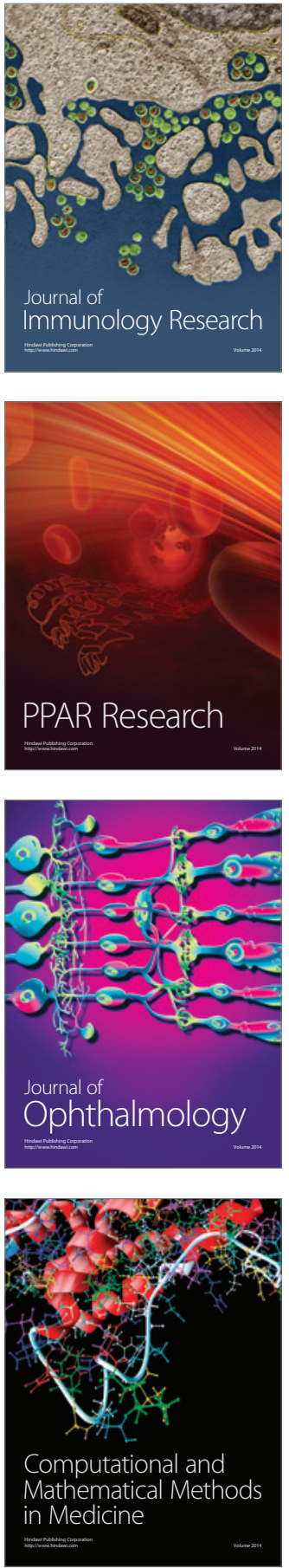

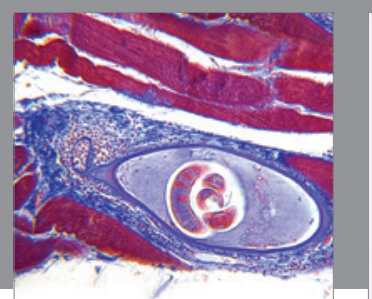

Gastroenterology Research and Practice

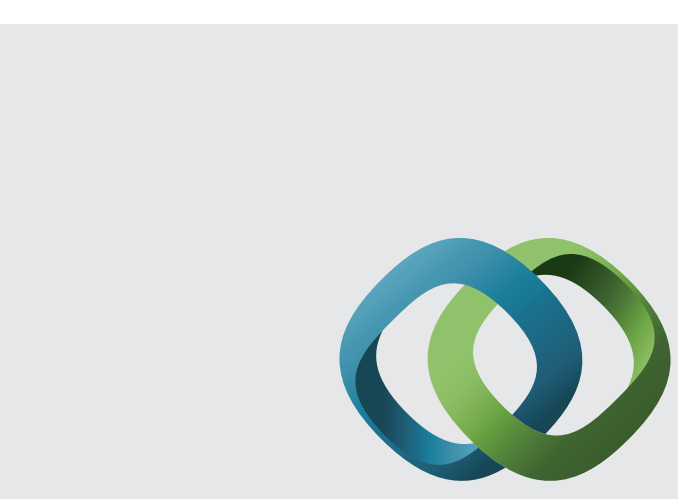

\section{Hindawi}

Submit your manuscripts at

http://www.hindawi.com
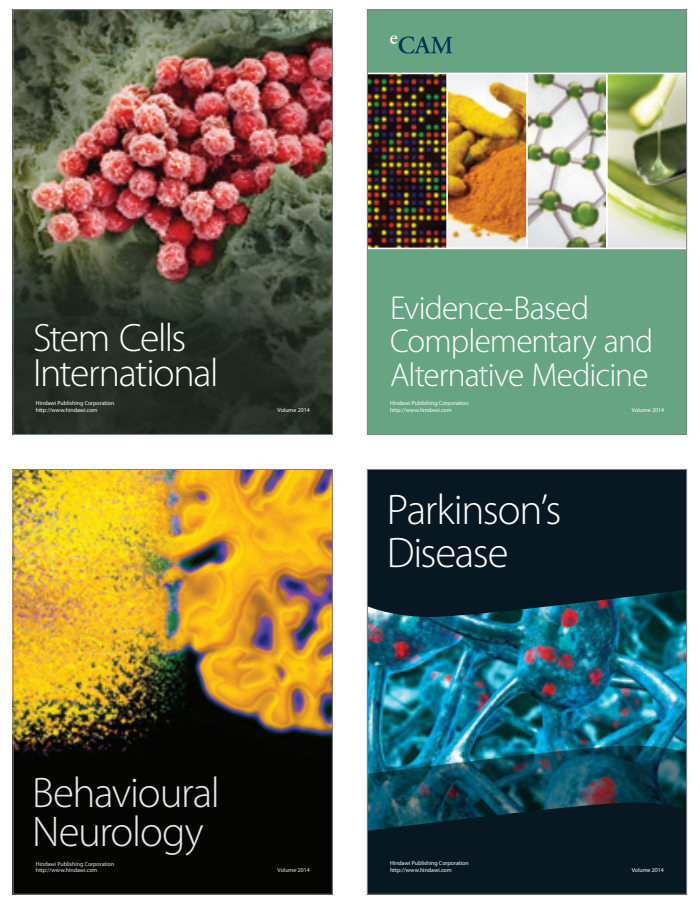
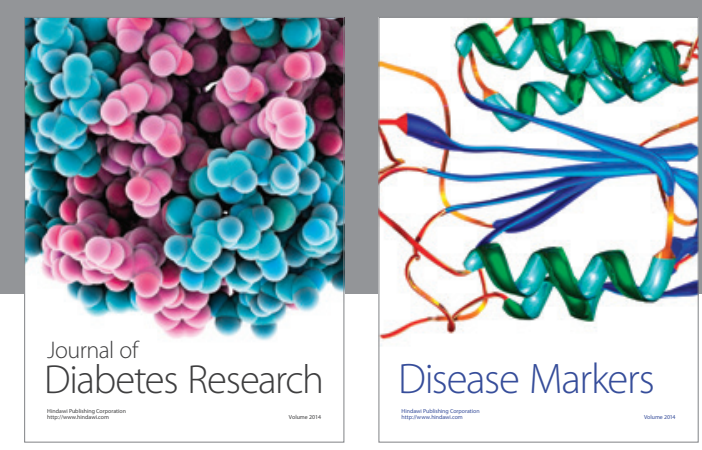

Disease Markers
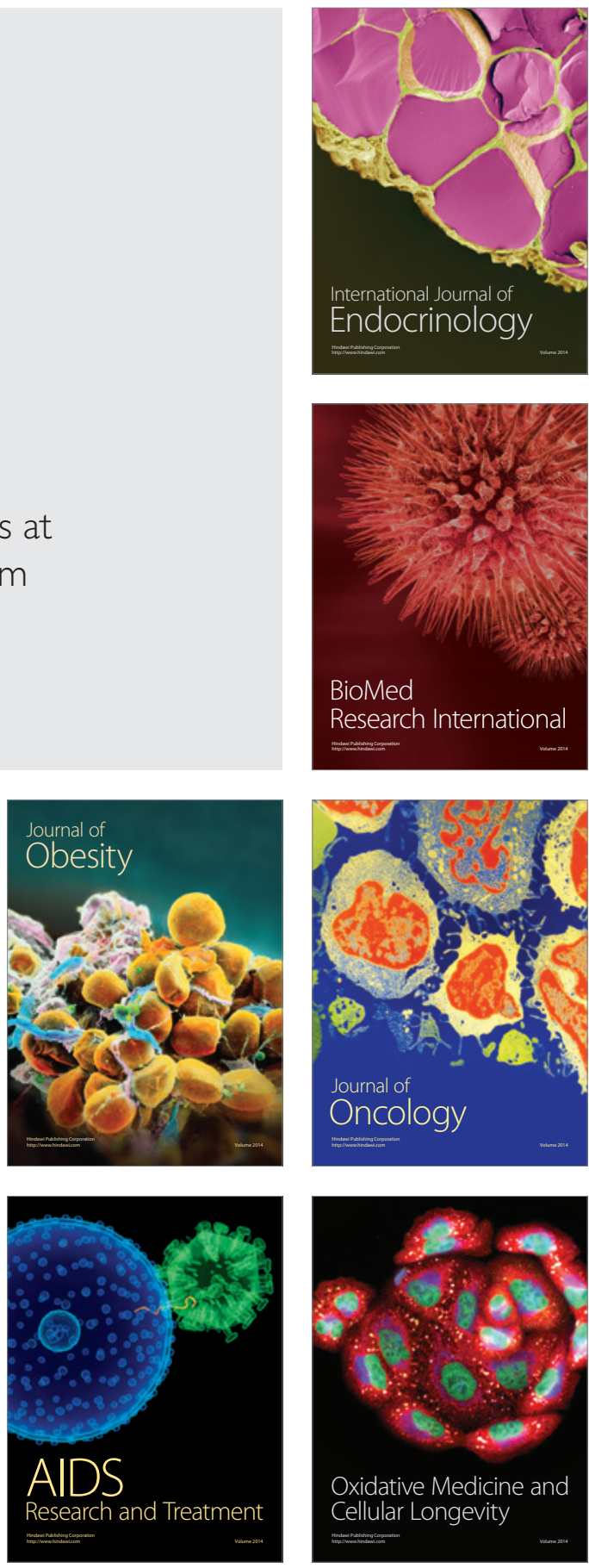